\title{
Hair It Is: Examining the Experiences of Black Women with Natural Hair
}

\author{
Tabora A. Johnson"1, Teiahsha Bankhead ${ }^{2}$ \\ ${ }^{1}$ Education Department, Medgar Evers College CUNY, Brooklyn, USA \\ ${ }^{2}$ Department of Social Work, California State University, Sacramento, USA \\ Email: TJohnson@mec.cuny.edu
}

Received 7 August 2013; revised 10 September 2013; accepted 16 September 2013

Copyright (C) 2014 Tabora A. Johnson, Teiahsha Bankhead. This is an open access article distributed under the Creative Commons Attribution License, which permits unrestricted use, distribution, and reproduction in any medium, provided the original work is properly cited. In accordance of the Creative Commons Attribution License all Copyrights (c) 2014 are reserved for SCIRP and the owner of the intellectual property Tabora A. Johnson, Teiahsha Bankhead. All Copyright @ 2014 are guarded by law and by SCIRP as a guardian.

\begin{abstract}
Who am I and how do I feel about who I am, are essential questions that help define and construct identity. For Black women and girls, identity is inextricably linked to their relationship to and presentation of their hair. Our research presents findings from an Internet based survey conducted with 529 Black women exploring their experiences when wearing their hair in its natural state (not thermally or chemically straightened). These are preliminary findings from the study with reference to the composition of the study participants and how they responded to key questions related to how they perceived when wearing their hair naturally.
\end{abstract}

\section{Keywords}

Black Women; Identity; Hair; Self-Esteem

\section{Introduction}

Who am I and how do I feel about who I am, are essential questions that help define and construct identity. For Black women and girls, identity is inextricably linked to their relationship to and presentation of their hair. Hair is important in many cultures and its meaning and symbolism vary depending on social and cultural context. For African people, hair is deeply symbolic, and its meaning extends into multiple dimensions of Black culture and life. This meaning is both deep and wide; in other words, hair may have spiritual and religious connotations. It may play an essential socio-cultural role [1-5] and at other times its meaning may serve as a method of self-expression [6-8]. Practitioners working with women and girls of African descent, who intend to have a culturally responsive relationship based on respect and value, must understand that part of getting to know their 
client/student may mean exploring the meaning of hair to the individuals they serve.

The first segment of this paper offers an extensive review of literature to orient readers on the socio-history of hair for people of the African Diaspora. Without a clear view of the historical and symbolic meaning of hair in the Black community, it becomes difficult to understand its centrality. Our research presents findings from an Internet-based survey conducted with 529 Black women exploring their experiences when wearing their hair in its natural state (not thermally or chemically straightened). These are preliminary findings from the study with reference to the composition of the study participants and how they responded to key questions related to how they perceived when wearing their hair naturally.

\section{Literature Review}

\subsection{Historical Role of Hair for Black Women}

To understand the centrality of hair to African people one must do so through the lens of an African worldview and cosmology, only then will the full scope of its importance be thoroughly understood. Throughout the ages, from the Ancient Nile Valley civilizations to the movement West and the establishment of Western African empires, hair has maintained a spiritual, social, cultural and aesthetic significance in the lives of African people $[2,7]$. Historically, hair has held significant roles in traditional African societies, including being a part of the language and communication system. For instance, during the $15^{\text {th }}$ century, African people such as the Wolof, Mende, Mandingo, and Yoruba used hairstyles as means to carry messages [2]. One of the unique features of African textured hair is its ability to be sculpted and molded into various shapes and forms. Hence, while hair may play an important role in the lives of people of all races, for people of African descent, this role is amplified due to the unique nature and texture of Black hair. Since antiquity, Black hairstyles have been known for their complexity and multifaceted nature, a notion that remains true today [6].

\subsection{Symbolism and Black Hair}

Hair was and continues to be used as a marker of various cultural indications. In Africa hair was used to denote age, religion, social rank, and marital status as well as other status symbols [2]. For example, during the Medieval African period $\left(12^{\text {th }} / 13^{\text {th }}\right.$ century), a young Wolof girl would partially shave her head to point out that she was not of marrying age. The extent of social messages in hairstyle choices did not end on the continent of Africa. As late as the 1980's Black men wore a style known as the high top fade, a hairstyle where the sides of the head are shaved with the top portion growing upwards and as high as possible. The style conveyed various cultural and political messages such as images of Africa, corporate logos, partner's names, and other symbols were etched into the hair or onto the scalp [2]. The high top fade was a modern day method of illustrating the multifaceted symbolism of Black hair - a thing that can be used as the message itself or to state a particular message. Additionally, true to African epistemology, spirituality has played and continues to play an essential role in Black culture [9]. Consequently, because of its integral function, hair has been and continues to be used to increase the potency of medicines and indigenous healing potions [2]. It is an understatement to suggest that hair is merely part of African cultural identity, as hair and identity are inseparable [10]. For both African men and women hair is intricately connected to cultural identity, spirituality, character make up, and notions of beauty.

Of particular importance to the African was the comb. The comb had cultural meaning that indicated one's particular group and other spiritual symbolism, personal history, and class status long before Europeans engaged in the mass enslavement of Africans in the $17^{\text {th }}$ century. Men carved these symbols and spiritual demarcations into their combs that were specifically designed with long teeth and rounded tips to untangle African textured hair $[2,3,11]$.

\subsection{Oppression and Repression of African Hair}

Europeans, who had long traded and communicated with Africans, knew the complexity and significance of Black hair. They were often struck by the various hairstyles that they saw within each community [11]. In an effort to dehumanize and break the African spirit, Europeans shaved the heads of enslaved Africans upon arrival to the Americas $[6,7,11]$. This was not merely a random act, but rather a symbolic removal of African culture. The shaving of the hair represented a removal of any trace of African identity and further acted to dehumanize 
Africans coming to the Americas in bondage [2]. Africans with cultural identities such as Wolof, Asantes, Fulanis, and Mandingos entered the slave ships, yet an enslaved unidentifiable people exited onto the shores of the Americas. Without their combs, oils and native hair recipes Africans were left unable to care for an essential part of themselves [2,11]. Europeans deemed African hair unattractive and did not consider it to be hair at all; for them it was considered the fur of animals and was referred to as wool or woolly [2,8,12]. In an analysis of Africans' hair [12], a White anthropologist, reported that the hair types ranged from peppercorn, tufted, matted, to woolly. He goes on to add that the hair's "spirality appears to have produced the matted condition. It is not the result of accumulated dirt or anything of that sort, as might appear at first sight" [12, p. 83]. This "spirality" refers to the unique nature of Black hair to spiral upwards naturally and form tightly coiled dense hair. However, instead of acknowledging its uniqueness, Black hair is described in pejorative terms. Words such as: peppercorn, matted and woolly, remain in the lexicon of people in the US, Africa, the Caribbean and worldwide, to describe Black hair. We observe that the descriptions that emerged in the 1800 and 1900's remain current irrespective of societal changes [2].

\subsection{Racialization of the Black Body \& Hair}

The atrocities of African enslavement and the forcible removal from their homeland created a new phenomenon; for the first time in history African beauty, body and hair was racialized and European features were the accepted standard of beauty. This meant that tightly coiled tresses were considered deplorable when pitted against the long, straight European hair that was considered beautiful and attractive. With the oppression and enslavement of Africans came the oppression of Black hair. From the arrival in the Americas to plantation life and beyond, history shows a common trend of repressing African hair $[1,2,4,6,7,13]$. On the plantation, the men who worked the fields wore their heads shaved, while women were expected to cover their hair with rough, course fabric because Europeans considered it unattractive and offensive [2,11]. Enslaved Africans who worked closer to the plantation "masters," wore hairstyles that emulated the dominant trends of the times, such as wigs in the $18^{\text {th }}$ century [2]. Africans on the plantations either had to emulate white people or cover their heads in effort to not offend Whites, a concept that carries into our present society, in a somewhat more nuanced manner.

\subsection{Black Hair Care, Beauty \& Entrepreneurship}

After two centuries of enslavement, a clear health and beauty consciousness was created through Black hair maintenance [6]. Due to centuries of persecution and oppression, Africans began to believe that lighter skin and straighter hair would assist them in attaining social and economic mobility [2,3]. This was in part due to the preferred treatment of biracial Blacks who often worked less physically demanding positions and received material goods from European Americans. Consequently, the $19^{\text {th }}$ century saw an increase in hair care and beauty product lines that were intended to lighten darker skin and straighten "nappy" hair [3]. The late 1800's gave birth to a Black hair care boom [10]. Two of the historic pioneers of the Black hair care industry are Madame C.J. Walker and Anna Turbo Malone [2,3,6,10], who created their hair straightening line in the late 1800's and launched their company in the early 1900's. Malone and Walker created lines that were specific to the hair needs of Black women. Malone urged, women of African descent to see themselves as African first [6]. The glaring contradiction lies within the fact that while urging African women to be themselves Malone created a product meant to straighten their natural, tightly coiled hair. This contradiction continues to be part of the struggle of many Black women, because the ideals are so deeply seated and have circulated from one generation to the next.

Although Malone created a hair care line specific to the needs of African American women before Walker, history has been more favorable to Madame C.J. Walker whose popularity greatly exceeds that of Malone's. Madame CJ Walker wanted Blacks to feel pampered and cared for and be given the opportunity to experience beauty rituals [2], something that had rarely if ever been experienced by Africans after being captured and brought to the Americas. Among the notable accomplishments of Walker is her popular straightening comb that she fashioned in 1905 [6]. Although not the inventor of the straightening comb, Walker made this tool accessible to Black women who desired straight hair. Instead of using a clothing iron or some of the other harmful methods utilized to accomplish the look of a straighter hair texture, African American women were able to more easily achieve a style that they felt would afford them greater social and economic mobility.

Walker's entrepreneurial efforts made a quantifiable impact on the African community in the United States and worldwide. Her products reached thousands of African women in the Caribbean and South America, as well 
as across the United States. Walker eventually became the first female self-made millionaire in the early 1900's in the United States $[2,3,6]$. Understanding the financial needs that often faced the Black community, Walker was a philanthropist who was known for giving generously to Black businesses, churches, communities, and individuals. Madame CJ Walker, at her death, employed over 100,000 African American women [3]. Walker's life and accomplishments are a clear indication of the significance of hair to the African community.

\subsection{Impact of the Civil Rights Era on Black Hair}

The 1960's and 70's ushered in a new wave of Civil Rights and racial pride for African people in the United States, the most identifiable marker of this pride and new movement was Black hair worn in its natural state. In particular, the Afro, a style accomplished when unlocked and unstraightened Black/African highly textured hair is not thermally straightened after washing, but combed upwards and outwards. During the 60's and 70's, the Afro hairstyle (also called the Natural) became symbolic of political change [2,6,8,13], Black self-love, intellectual historical knowledge, and Black Power $[4,6]$. This was the era where hair that was once considered "bad," because of its tight curl, was now considered "good" because it was worn "free" from chemical or heat processing restraint [2]. In addition to being symbolic of beauty, the style was also representative of the social rebellion and civil revolution underway. The Afro demonstrated that something new was happening in the United States and that society was experiencing tantamount changes. It was essentially illustrative of the freeing of the Black mind, and those without an Afro were frowned upon for remaining in a captive state of mind. The Afro left a significant impression of Black power and civil unrest in the United States $[2,3,4,6,8,10,13]$. While society has undergone various socio-cultural and sociopolitical shifts, there are still those who see the Afro as a sign of militancy and Black power $[6,8,10,13]$.

\subsection{Symbolic Representation of Black Hair and Its Importance to Black Female Identity}

For many women of African descent, hair is emotive, symbolic and an inseparable part of their identity [6,8,10]. In a study conducted by Chapman [6] participants recalled hair related childhood experiences with their mothers and grandmothers. A common thread was a message from the elders emphasizing, "your hair is your crown and glory". One of the current authors distinctly recalls a conversation with a middle school student who refused to go to class because her hair was "not done." A colleague, a White female school counselor, felt as though she did not have enough cultural competency to facilitate this young girl's understanding of the importance of instructional time versus the shame of seemingly unkempt hair. It took over half an hour of this author's counseling and a demonstration of a significant cultural connection, including the offering of resources and ideas of how to resolve the concerning hair issues, to convince this young girl to return to class. Unfortunately, this is one of many examples of the emotive role hair plays in Black women's self-concept, identity development, and life experience [8]. The concept of "getting” one's hair "done" holds paramount value with African communities in the United States and globally [6]. The Black hair care industry amasses over half a trillion dollars annually [14]. In 2012 the leading Black hair care companies saw \$185M in revenue [15].This industry has been able to withstand the latest US recession as sales have yet to experience a significant decline. These staggering figures reveal just how much hair and its proper care play an undeniably critical role in the lives of Black people.

\subsection{Black Hair Care and the Role of Normalized Whiteness}

In the Western world, Black identity has been constructed to normalize whiteness [4]. Thus, society deems Blacks and other people of color as the "other" [6]. While hair is significant to Black women, hair is a part of every woman's identity to some degree. Hair is a distinct "marker of womanness, gender and identity" [6]. Because of this "othering" of Blackness, which includes Black hair, Black women have historically been seen as inhuman objects. Black women's femininity, body, and physical features have been under attack since the capturing of Africans who were removed from their homelands with force and disregard for their humanity. Hair is particularly meaningful to women of African descent because it has been "displayed as beautiful and decadent and used to display culture, beauty and spirituality" [6, p. 25]). This traumatizing phenomenon coupled with its socio-cultural, historic, and spiritual relevance has resulted in a hyper-awareness of hair for Black men and women, but in particular Black women and girls. Of all physical features, hair is the one most easily transformed 
[1]. The often taken choice to straighten natural Black hair has clear historic and psychological underpinnings [16]. Black women spend more money, as high as three times as much, on hair care [14] than any other racial or ethnic group of women [3].

Power [6] and political relations [2,4,6,13] can be studied through Black hair. For instance, the Afro or "Natural" continues to symbolize Black power and militancy. "When the New Yorker set out last summer [2008] to satirize [the United States First Lady], Michelle [Obama] as a militant, country-hating, black radical, it was no coincidence that the illustrator portrayed her with an Afro [16, p.56]. The Afro is equivalent to militancy and revolution [10], and it evokes strong feelings of power and political confrontation for Blacks and Whites alike. Hair also offers the opportunity to examine the politics of women of African ancestry's body. One simply has to examine advertisements in popular media. They are typically void of Black women and if featured the Black women represented are usually those with Caucasian features (i.e. straight hair, less developed lips, and small straight noses) as opposed to those with what is commonly thought of as distinct African features (i.e. tightly coiled/kinky hair, full lips, broad noses, etc.). Misrepresented, distorted or missing images send direct and indirect messages about what it means to be beautiful, and have beautiful hair and a beautiful body, as well as who has the power to define these beauty standards. It becomes evident that women of African descent must resist powerful oppressive and unfavorable forces that would have them believe that their hair, skin, and physiques are naturally inferior. Thus, Black hair has been and continues to be symbolic of both power relations and resistance.

\subsection{Hairstyle and Social Status}

"Black people tend to assume that a certain (hair) style say(s) something about a person's socioeconomic status" [2, p.158]. Hairstyles have historically represented social class and political stance [3,6]. Since the days of chattel slavery in the Americas there have been contradictions over the meaning of wearing Black hair straight. During the 1900's many Black women denounced hot combing and chemical relaxing hair straightening methods, since these practices were perceived to emulate European beauty standards [2,3,6]. Some disagreed with this perspective, arguing that hair straightening was simply a style option and not an attempt to become white $[2,6]$. “Conking," a popular term used in the early to late 1900's to refer to chemically straightening African highly textured hair with lye, was a popular trend in the mid 1900's [6]. The contradiction regarding the meaning of hair straightening is most evident and popularized in Malcolm X's autobiography. Upon transitioning from Malcolm Little to the more self-aware, race conscious, social activist, El Hajj Malik El-Shabazz, he removes his "conk" (chemicals) from his hair to indicate a physical, social, political, and spiritual transformation [17]. This symbolic patterning of removing the oppressive mind/thinking (chemicals) from the hair to free one's mind and embrace the natural self was also evident in the 1960's as discussed previously. Today there is an increasing emergence of Black women who are typically young (20 - 35), who are "transitioning" from using chemicals to straighten their hair to wearing their hair naturally [18]. For these college-educated, modern, young Black women, hair continues to indicate social and economic status and for some even a woman's character and personality.

\subsection{Racism, Sexism and "Bad" Hair-Ism}

Europeans' physical attributes have been and continue to be the yardstick for beauty in mainstream society [1-4, $6,8,13]$. The beauty standard has created dichotomies as binary opposites to distinguish African features from European features such as kinky and straight, long and short, dark and light, good and bad [6]. These beliefs have seeped deep into the psyche of many communities of color. Particularly in African communities throughout the Diaspora, to have "good hair," or a "good nose" means that one's hair is closer in texture to that of people of European descent or that the nose is straight and resembles that of a European ideal. Beauty has been socially and politically constructed to emulate those in power, White people. In her research study of Black hair among Black women enrolled in study aboard programs, Chapman [6] reported that a standard of beauty is a tool used to control the image and esteem of the woman. Thus, the ideals surrounding who and what is beautiful have real consequences in the lives of Black women. Consequences that often impact their lives socially, economically, and politically.

To wear natural Black hair is a political act $[10,13]$ within itself, since depending on the environment such hair may be deemed socially and politically unacceptable. In 2007, Glamour magazine editor, Ashley Baker, 
gave a presentation entitled “The do’s and don'ts of Corporate Fashion,” to over 40 lawyers in New York City. The first "don't" slide depicted a Black woman with an Afro, with the caption "say no to the fro". She then commented, "As for dreadlocks: How truly dreadful!" She went on to add that it was "shocking" that some people still think it "appropriate" to wear those hairstyles at the office. "No offense", she sniffed, but those 'political' hairstyles really have to go" [6, p. 70]. These statements are clear indications of structural racism and offer an indictment on Black women's beauty, and mere physical characteristics. After all, is it really a choice if a people are routinely criticized for simply wearing their hair as it naturally grows from their scalp? It is also evidence of race privilege- a White woman has the authority to define what is considered beautiful and what is not. There is also then an assumption that others must also hold these same beliefs to be truths and cooperate with White hegemony. One of the issues is that this form of structural racism has economic, social, and political consequences for Black women.

\subsection{Identity \& the Black Body: A Multilayered Oppression}

Black women face a double "othering” through gender and racial oppression as Black hair is politicized and racialized by class and gender [13]. Chapman [6] conducted a research study of 20 Black women who were ethnically diverse (Continental African, African Caribbean, African American, bi-racial) and had previously participated in a study abroad program. Chapman conducted interviews to investigate African and European cultural influences on African American ideas about beauty, hair, and identity. She found that Black women's hair is subjugated to restriction and rules that Black men do not likely confront. The concept of "othering" had real implications in the lives of Black women. One participant was asked, "to get rid of her vibrant red Afro" [6, p.68]. Another participant was told that her Afro was "too out there". It is apparent that the dominate message is that if a Black woman is working in a corporate setting it is assumed that she will follow the ascribed standards of dress, speech and behavior, which is normed on Whiteness. Since the Afro is commonly considered symbolic of resisting White supremacy-it was thus "unacceptable" in the corporate environment. In another setting, a participant who was a schoolteacher was informed that she was able to wear her natural hair as long as it was "neat". This teacher did not define the construct of "neat," it is instead designed through a Eurocentric concept of beauty, which is oppressive to African people. The above examples illustrate the resiliency and strength that Black women must display in order to do something as simple as wear their hair as it naturally grows from their scalp.

Racist views of the Black body impact the identity and identity development of Black women and girls $[4,6]$. Historically, skin color [17] and hair texture [4,6] have shaped the lives of Black women in the Caribbean, United States and throughout the African Diaspora. Women of color feel great negative effects of skin color and [19-22] hair texture prejudice [1-4,6,13]. From birth women of African descent are taught through the popular cultural messaging that there is something wrong with them based upon their hair and skin [13].

Beauty is related to the transference of power. "Good" hair is perceived as the hair closest to White people's hair-long, straight, silky, bouncy, manageable, healthy, and shiny; while "bad" hair is "short, matted, kinky, nappy, coarse, brittle and wooly" [6, p.28]. Consequently, terms such as "good hair" have become a code for White, straight hair, granting more power and social capital. Similarly, "bad hair" is a code for highly textured African hair and signifies less social capital [6]. Erasmus [13] tells of a grandmother's gesture to her granddaughter regarding her "Nigger-hair (grandmother laughs) 'You've got real nigger-hair' " [13, p.13]. The beauty myth of the good/bad hair dichotomy where straight hair is the "most desirable" and thus "good" were created during the colonial era [19] and the concept continues to be rampant throughout the African Diaspora. Body parts are used to highlight racial inferiority, thus curly, kinky hair is seen as a badge of inferiority [2]. In the United States, Caribbean, Africa and wherever African people reside, African textured curly hair carries a social stigma [7]. For women of color, in particular Afro-Latinos, Latinos, or other people of African descent, light color skin continues to serve as social capital [19,22]. Hair stories are very similar and almost identical wherever African women live [13]. These are painful narratives for likely a majority of Black women who grow up hearing statements about their hair being too nappy or their skin being too dark. Hair mediates the effect of skin color, so if one has dark skin but looser curls or longer hair these positive attributes act to lessen the "burden" of dark skin [4].

Among Black women there is a belief that social and cultural capital are attained through hair status. This belief is based upon lived experiences, cultural messages and societal cues and it is disseminated from one generation to the next [22]. Chapman [6] found that her bi-racial participants were more likely to be approached by 
men because they had "desirable hair”. Straight hair or hair of a straighter texture is seen a symbol of sexual desirability $[3,6]$. The idea of hair as a tool to allure a mate has a long history throughout the Americas. During the late 1800 and 1900's advertisements from White, manufacturers targeting a Black audience indicated that their products would add to African women who "lacked", beauty and feminine grace [2,3]. The ads played upon already held notions of hair and race inferiority that were prevalent in White and Black communities. Young Black girls learn at very young ages that their hair will help them attract a man [1]. In the popular novel Their Eyes Were Watching God, by Zora Neale Hurston [23], the main character Janie ties her hair up in the store under her husband's orders so that other men will not touch her. Hair is a tool for sexual desirability across races and ethnic groups; however, the issue within the African community is that the "type" of hair that is often desired [1] is not necessarily one that many Black women naturally possess. In other words, straight textures are often desired, but it is not the natural texture of most women of African descent. As African American men attend school and are socialized and acculturated with the dominant White culture, their preferences are influenced [5]. This means that men, just like women are conditioned to desire textures that more closely mimic a White European ideal. Some Black women will often "shift" to adapt to societal norms and be accepted by White people and Black men [6]. Some Black women have chosen a permanent shift in wearing their hair straight because their husbands or mates do not like their "curly/kinky" hair [1]. For Black women discrimination against their person can lie within the walls of their very homes.

Hair is a marker of femininity [6], so to restrict or demean one's hair is a direct attack on women's being. This implies that when the hair is covered —as it had to be on the plantation or other places where African women existed, they were deemed less feminine and thus less womanly [1]. While many Black women's accomplishments may be impressive and outstanding, reflections of their imagery may depict a less impressive self-regard, because of continuous comparison to their European-American counterparts. Young Black girls are conditioned to admire the woman with "long, light, hair and beautiful blue eyes" [3], while loathing their "nappy" hair. Many women have internalized beliefs that their hair, skin, and body are sub-par to that of women of European descent.

The Black body has been socially and culturally constructed by a racist and sexist society and is seen as "vulgar" [6,24-26]. Historically the Black female body has been a sexual object-something to objectify and use [24-26]. The story of Saartjie "Sarah" Baartman [25,26] illustrates both the historic and modern perspectives of the Black body. Baartman was a South African woman with steatopygia (large buttocks), as well as large hips, breasts and full lips who was taken from her native land in 1810 to be in a circus display. She was placed in a cage and forced to dance and perform other human tricks because of protuberant buttocks. Completely dehumanized and striped of her identity and basic rights to live a peaceful life with human dignity, Baartman was forced to perform under any circumstance. Solly, Moojen \& Lindfors [26] share one spectator's account, "She was extremely ill, and the man insisted on her dancing, this being one of the tricks which she is forced to display. [She] pointed to her throat and to her knees pleading with tears that he would not force her compliance. He declared that she was sulky, produced a long piece of bamboo, and shook it at her: she saw it, knew its power, and, though ill, delayed no longer" (p. 135). Even after her death her body was placed on display in a British museum [24]. It was not until 2002 that this woman's dead body was returned to South Africa so the interment of her remains could find an honorable final resting place. This story illustrates how many white people in the mainstream public seem to have a morbid fascination with the differences of the Black woman's body. Even in death the Black body was disregarded and objectified. Large buttocks, breasts, hips, and lips have been viewed more as sexual toys than "regular" parts of the anatomy to be respected or admired.

Black hair has not escaped this notion of vulgarity. Black hair continues to be seen as wild, untamed, and frightening [4]. One popular and normative way to describe Black hair is "kinky". The Merriam-Webster dictionary gives two definitions of the word kinky: 1) closely twisted or curled; 2) related to, having or appealing to unconventional tastes especially to sex; also: sexually deviant. How is it that this word both describes the texture of many variations of African hair and sexual deviance? This is a poignant example of the powerful cultural implications of Black hair. Understanding these socio-cultural underpinning brings clarification to why the Black body and hair at times evoke feelings of fear and promiscuity.

Young girls growing up in a society that deems their physical appearance unnatural and unattractive are taught in their formative stages to dislike themselves. Scholars [27-29] have illustrated the harmful effects of negative self and racial esteem and its implications on academic achievement. Having a positive racial identity increases self-concept and leads to greater school success [30-37]. The negative psychological implications of 
being taught to dislike one's self cannot be ignored, as the cycle of has lasting effects within the Black community.

\subsection{Black Hair Care and Its Consequences}

Upon forcible arrival to the Americas, Africans lost control of both their lives and their physical bodies. Their bodies were subjected to traumatic physical harm including but not limited to: beatings, maiming, and rapes among other gruesome acts of violence experienced at the hands of white people. Losing control of one's physical body causes serious and long lasting psychological trauma [38]. This has led to what DeGruy [38] terms as posttraumatic slave syndrome and what we will refer to here as the multigenerational traumatic legacy of slavery (MTLS), since the effects of African enslavement are actively noticeable in modern society. Within the Western frame, the body is a thing to be controlled [6] with hair being the most controllable physical feature [1]. Consequently, Africans have had a long history of using drastic measures to attain "desirable” hair.

Straightening highly textured African hair often requires the use of toxic chemicals or heat intensive tools such as a straightening comb or flat iron, which may be heated to over 400 degrees. Hair relaxers are used by millions of Black women and expose them to various chemicals through scalp lesions and burns [39]. In addition, harmful chemicals cause minor to severe hair loss including balding, burns, and color change [2,3,39-41]. DeGruy (2000) noted that chemicals used in hair relaxers caused injury in the mouth and esophagus when ingested and such products must therefore be labeled poisonous. Wise et al. [39] tested hair relaxer use in relation to uterine leiomyomata (fibroids) incidence among 23,580 premenopausal Black women. Women who used chemical relaxers had higher incidents of uterine fibroids than those who never used relaxers. More precisely, 7146 cases of uterine leiomyomata were reported as confirmed by ultrasound $(n=4630)$ or surgery $(n=2516)$. The incidence rate ratio comparing ever with never use of relaxers was 1.17 (95\% confidence interval (CI): 1.06, 1.30). The findings indicate that hair relaxer use increases uterine leiomyomata (fibroid) risk. There are clearly dire risks involved with continuing the use of chemical relaxers that often require application every 6 - 8 weeks after the new hair grows. In cases where parts of the hair cannot be straightened, for example, what is often referred to as "the Kitchen" the part of the hair that resists straightening-many women cut or shave what is sometimes the rear part of their heads [13].

Hair texture is an important part of beauty, thus many women of African descent will knowingly take risks to attain "beauty". Etemesi [41] conducted research in Kenya with 245 women who ranged from 15 - 51 in age and used relaxers to "manage" their hair and look "beautiful". One hundred and thirty-four women (67\%) had problems with the relaxers used (at least once); the injuries included those previously noted. Despite these harms, the women did not stop using the products. In the 1990's Rio Corp came out with a new product that promised to straighten hair naturally [2,3] instead, after using the product hundreds of women suffered from permanent baldness and other scalp injuries [41]. These risky behaviors, to many, are worth a chance of being seen as beautiful in the eyes of society.

\subsection{Where Are We Today?}

There is a growing trend among Black women to return to their "natural roots" and eliminate the use of chemical strengtheners. In 2010, Design Essentials, a hair care company, conducted a study to measure the popularity of natural hair; they found that while $26 \%$ of women eliminated chemical relaxers in 2010 , there was a 10 percent increase in 2011 making the new figures 36\% [42]. In addition, USA Today and Mintel [42], a consumer spending and market research firm, found that relaxer sales have decrease 17 percent since 2006. Cyntelia Abrams, a marketing coordinator for Design Essentials commented, "Natural hair has been a movement for several years. What we're seeing now is a confirmation that this is a lifestyle that is very important to a lot of women" [42]. Unlike the natural hair movement of the 1960's and 1970's today women of African descent are choosing in increasing numbers to wear their hair naturally simple for the sake of their hair. For many, it is less about a political statement and more about self-acceptance and the opportunity to embrace their natural tresses in its natural, unaltered state.

\section{Methodology and Design}

An Internet-based survey research endeavor was undertaken by the two authors to explore the responses Black 
women received in society when wearing their hair in its natural state. This was a pilot project of a larger mixed methods study planned on Black Hair Narratives. The study used a quantitative, exploratory, online survey research design. We were interested in examining the relationship between discrimination experienced by Black women and their comfort and thoughts about wearing their hair in its natural state.

\subsection{Sample}

The population of interest included adult women of African descent living in the United States. A convenience sample of Black women was solicited from the personal contacts of the two researchers who identify as African American and African Jamaican. Researchers constructed a Facebook page for the study under the name, Black Hair Narratives and encouraged potential participants to ask questions and engage in discussion about natural hair using this forum and through direct email exchange with the researchers. The researchers then sent a number of group email messages to their personal and professional contacts. Both women are members of a number of professional Black women's organizations in New York City and the San Francisco Bay Area, and they used these contacts to generate interest in the study. Respondents were encouraged to complete the survey online, as well as forward the email message and link to additional personal and professional contacts. Over a 3-month period, 529 people responded to the survey.

\subsection{Instrument}

The survey included 52 questions that explored responses to Black women when they wore their hair in its natural state. The purpose of this project was to explore measures of hair esteem levels. We used the Bankhead/Johnson Hair Esteem Scale (see Appendix A), adapted from Rosenberg's [43] self-esteem scale (see Appendix B) to gain understanding how they examined how hair esteem relate to self esteem and discrimination experiences of Black women. We were interested in whether Black women who wear their hair naturally (not straightened nor chemically altered) would report unfavorable responses from their workplace colleagues, friends, family, and/or strangers.

The survey consisted of mostly closed ended Likert scale and nominal type questions. The survey included 6 distinct sections, they are; 1) general questions about hair styles worn and hair texture, 2) acceptance of natural hair in different environments, 3) responses received from different social groups, 4) discriminatory experiences, 5) a Black "hair-esteem” scale and Rosenberg's Self-Esteem Scale, and 6) demographics. The survey questions explored the relationship that respondents have with wearing their hair in its natural state, as well as how they were received by distinct social groups.

\subsection{Data Analysis}

Data were analyzed using IBM SPSS Statistics 20.0, the commonly used statistical software package for analysis in the social sciences. Data was run for frequencies of responses on individual variables related to the above mentioned survey areas, including demographics.

\section{Findings}

\subsection{Who Were the Respondents in the Survey?}

Demographics of survey respondents. Respondents to the survey represented a wide range of diversity among demographic characteristics within the context of being women of African descent (see Table 1 for raw demographics values). Participants indicated that they belonged to 7 different racial/ethnic categories with representation in the African American/African Canadian group being the highest at $72 \%$. The median age of women in the study was 32 years of age, however, participant ages ranged from 18 to 71 . Annual household income ranged from $\$ 0$ to $\$ 25,000$, to over $\$ 250,000$ with the median household income being in the $\$ 46,000$ to $\$ 60,000$ range. The median highest level of education achieved was "some graduate school" with the most common response to this question being receipt of a graduate degree $(n=141,32.8 \%)$. Most people lived in New York, however, 29 states and the District of Colombia, Canada, the Caribbean, Europe and Asia were represented in the sample. The most prevalent work sector was work in education.

A full $96 \%$ of respondents indicated that they at least sometimes wore their hair in its natural state. When 
asked if women who wore their hair naturally manipulated it to create curl or wave definition when going out in public, 63.5\% indicated that they did. How often did respondents wear their hair naturally? A full $41.8 \%$ of respondents indicated that they wore their hair naturally on a daily basis or 30 days each month (see Table 2 for raw values). About 58\% of respondents indicated that they wore their hair straightened at least 1 day each month.

\subsection{Responses When Wearing Hair in Its Natural State}

Respondents indicated their perceptions of environments in which they were in that were accepting of Black women wearing natural hair. Overall, the women felt that they were in very or somewhat accepting environments at work, in their families, in their communities and among friends (see Table 3 for raw values). Respondents were also asked about favorable responses that they experienced while wearing their hair naturally. They consistently indicated that they received somewhat or very favorable responses to wearing their hair naturally with co-workers, supervisors, in their communities, with family members, in their friendship circles and with their romantic partners (see Table 4 for raw values).

Women were asked whether they have been subjected to discrimination due to wearing their hair naturally. About $1 / 3^{\text {rd }}$ of the respondents had experienced discrimination because of wearing their hair in its natural state (see Table 5 for numeric details).

Women were asked whether they were teased, taunted, or ridiculed in specific social groups because of wearing their hair in its natural state. The respondents indicated that the groups they most often received negative

\begin{tabular}{|c|c|c|c|}
\hline Variable & $\mathrm{n}$ & Valid \% & Highest Frequency \\
\hline Race & 304 & 72.2 & African American \\
\hline Age & 418 & 79 & Median $=32$ years \\
\hline Annual Income & 62 & 14.6 & $\$ 46,000-\$ 60,000$ \\
\hline Highest Education Level & 141 & 32.8 & Graduate Degree \\
\hline State & 111 & 26.9 & New York \\
\hline Work Sector & 130 & 24.6 & Education \\
\hline Ever Wear Hair in Natural State & 443 & 95.9 & Yes \\
\hline Manipulate Hair to Create Definition & 294 & 63.5 & Yes \\
\hline
\end{tabular}

Table 2. Days per month hair worn naturally.

\begin{tabular}{ccc}
\hline Variable & $\mathrm{n}$ & Valid \% \\
\hline Natural hair worn daily (30 days) & 221 & 41.8 \\
Wears straightened hair some days & 308 & 58.2 \\
Total & 529 & 100 \\
\hline
\end{tabular}

Table 3. Accepting environments for black women \& natural hair.

\begin{tabular}{ccc}
\hline Variable & $\mathrm{n}$ & Valid \% \\
\hline Work & 408 & 90.3 \\
Family & 409 & 90.3 \\
Community & 421 & 93.4 \\
Friendship & 439 & 97.3 \\
\hline
\end{tabular}


Table 4. Favorable social group responses to black women wearing natural Hair.

\begin{tabular}{ccc}
\hline Variable & $\mathrm{n}$ & Valid \% \\
\hline Co-workers & 416 & 93.7 \\
Supervisors & 387 & 89.2 \\
Community & 421 & 94.6 \\
Family Members & 395 & 89.1 \\
Friendship Circle & 436 & 87.4 \\
Romantic Partner & 396 & 91.4 \\
\hline
\end{tabular}

Table 5. Subject of discrimination because of natural hair.

\begin{tabular}{cccc}
\hline Response & $\mathrm{n}$ & Percent & Valid \% \\
Yes & 131 & 24.8 & 29.7 \\
No & 310 & 58.6 & 70.3 \\
Missing & 88 & 16.6 & \\
Total & 529 & 100 \\
\hline
\end{tabular}

responses from were family members (43\%), strangers (28\%), and friends (25\%). Ironically, the friendship group was also the group offering the most favorable responses and support for wearing natural hair (see Table 6 for raw values).

Respondents were asked how common they believed discrimination against Black women was when wearing their hair in its natural state (see Table 7 for raw data). A significant percentage of the respondents (47\%) indicated that they did "not know", or they skipped this question. Of those who did respond, they believed that Black natural hair discrimination was somewhat or very common (85\%).

Finally, respondents were asked the degree to which they felt that they were discriminated against as a result of wearing their hair naturally. Only $3.2 \%$ of respondents indicated that they were very much discriminated against, however about $25 \%$ experienced some or very much discrimination. It is important to note that a full $74 \%$ of respondents indicated that they experienced no discrimination or not very much as a result of wearing their hair in its natural state (see Table 8 for raw values).

\section{Discussion}

This study has found that in the sample available, $95 \%$ of the women wore their hair naturally at least some days. Of these women, they tend to feel that they are accepted in multiple social environments and they received favorable responses from most social groups. When they experience teasing, taunting, or ridiculing about their hair in its natural state, it is usually from family members, friends or strangers, but not co-workers or supervisors. While 84.5\% of respondents feel that discrimination targeting Black women for wearing their natural hair effects Black women, only 3\% indicated that they have been very much affected, and $23 \%$ indicated that they were somewhat affected.

These preliminary findings challenged the expectation that they researchers had upon approaching this study. We were surprised to find that so many Black women indicated frequently wearing their hair naturally while experiencing favorable responses and feeling accepted in multiple environments. As a cautionary note it is important to remember that the sample for this study includes a relatively young, highly educated group of Black women who likely wear their hair naturally more than most in the general population of Black women. Could it be that higher socioeconomic status is associated with a greater likelihood of wearing Black hair in its natural state, and having a favorable social response for doing so?

While large scale survey research methods have not historically been employed to assess feelings about natural hair wear among Black women, the researchers believe that the findings from this study may indicate a new and progressive trend towards natural hair styles and societal acceptance, particular among younger, highly 
Table 6. Teasing, taunting or ridiculing as a result of wearing black natural hair.

\begin{tabular}{ccc}
\hline Variable & $\mathrm{n}$ & Valid \% \\
Co-workers & 82 & 18.3 \\
Supervisors & 32 & 7.2 \\
Family Members & 194 & 43.3 \\
Friendship Circle & 111 & 24.8 \\
Strangers & 123 & 27.5 \\
\hline
\end{tabular}

Note. $\mathrm{n}$ refers to frequency of negative response participants received from specific subgroup.

Table 7. General discrimination against black women for wearing hair naturally.

\begin{tabular}{ccc}
\hline Variable & $\mathrm{n}$ & Valid \% \\
\hline Not at all common & 9 & 3.2 \\
Not very common & 35 & 12.4 \\
Somewhat common & 161 & 56.9 \\
Very common & 78 & 27.6 \\
Missing or Don't Know & 246 & \\
Total & 529 & 100 \\
\hline
\end{tabular}

Table 8. Discrimination that respondents have experienced due to wearing natural hair.

\begin{tabular}{ccc}
\hline Variable & $\mathrm{n}$ & Valid \% \\
\hline Not at all & 114 & 32.9 \\
Not very much & 143 & 41.3 \\
Somewhat & 78 & 22.5 \\
Very much & 11 & 3.2 \\
Missing or Don’t Know & 183 & \\
Total & 529 & 100 \\
\hline
\end{tabular}

educated women of African descent.

\section{Implications for Identity Development}

There is an association between favorable responses from society, earning middle class income, having advanced degrees, and wearing hair naturally among Black women. We also found that Black women who wear their hair naturally generally felt better about themselves. We maintain that feeling good about oneself leads to greater life and academic success. The narrative that deems it necessary for Black women to wear their hair straight in order to attain success is challenged by our research findings and suggests that this conceptualization may be outdated, particularly among younger, more highly educated and upper or middle income Black women. It is important that we teach Black women and girls self-acceptance of their natural hair and how to have a positive natural hair identity. No longer should it be acceptable to state that one must conform to European ideal of beauty in order to gain academic success and overall well-being. We put that forth a new narrative that Black women can wear their hair in its natural state, feel good about themselves and achieve financial and academic success.

\section{Significance and Conclusion}

This study is significant because it emphasizes the importance of natural hair for Black women and their devel- 
oping relationship with it. Minimizing the role of hair in lives of the African people continues the trend of marginalizing Africa and her people. The long-term impact of the dismissal of a group's cultural identity cannot go ignored. Many may feel as though hair was not an important academic research topic, but we reject this notion because of the evidence of mental and emotional damage caused by such claims. We argue that young black girls need positive images of themselves that allow them to feel normal in an oppressive society. We hurt the spirits of our girls with messages that they are inferior when we reject any aspect of their natural physical beings, cultural experiences, or authentic lives. It is crucial that as a society, we send the message to Black women and girls that they are worthy of admiration and respect in their natural states. Hair plays a crucial role in identity formation that cannot be ignored. Giving voice to this issue sends a message of self-acceptance, which is necessary for well-being and overall health.

\section{References}

[1] Ashe, B.D. (1995) "Why don’t he like my hair?” Constructing African-American Standards of Beauty in Toni Morrison’s Song of Solomon and Zora Neale Hurston’s Their Eyes were Watching God. African American Review, 29, 579592. http://dx.doi.org/10.2307/3042151

[2] Byrd, A. and Tharps, L. (2001) Hair story: Untangling the roots of black hair in America. St. Martin’s Press, New York.

[3] Rooks, N. (1996) Hair raising: Beauty, culture and African American women. Rutgers University Press, New Brunswick.

[4] Tate, S. (2007) Black beauty: Shade, hair and anti-racist aesthetics. Ethnic and Racial Studies, 30, 300-319. http://dx.doi.org/10.1080/01419870601143992

[5] Webb, T., Looby, J. and Fults-McMurtery, R. (2004) African American men's perceptions of body figure attractiveness: An acculturation study. Journal of Black Studies, 34, 370-385. http://dx.doi.org/10.1177/0021934703254100

[6] Chapman, Y. (2007) “I am not my hair! Or am I?”: Black women’s transformative experience in their self perceptions of abroad and at home. Master's thesis. http://digitalarchive.gsu.edu/anthro_theses/23

[7] Dash, P. (2006) Black hair culture, politics and change. International Journal of Inclusive Education, 10, 27-37. http://dx.doi.org/10.1080/13603110500173183

[8] Thompson, C. (2009) Black women, beauty, and hair as a matter of being. Women's Studies, 38, 831-856. http://dx.doi.org/10.1080/00497870903238463

[9] Ani, M. (2006) Let the circle be unbroken: The implications of African spirituality in the Diaspora. Nkonimo, New York.

[10] Jere-Malanda, R. (2008) Black women's politically correct hair. New African Woman, 14-18.

[11] Morrow, W. (1973) 400 years without a comb: The untold story. Black Publishers, San Diego.

[12] Gates, R. (1957) 98. Forms of hair in South African races. Man, 57, 81-83. http://dx.doi.org/10.2307/2794242

[13] Erasmus, Z. (1997) “Oe! My hare gaanHuistoe”: Hair-styling as Black cultural practice. Race, Identity and Change, 32, 11-16.

[14] Grenee, H. (2011) What spending a half a trillion dollars on hair care and weaves say about us. The San Diego Voice and View Point.

http://sdvoice.info/what-spending-a-half-a-trillion-dollars-on-hair-care-and-weaves-says-about-p1005-101.htm

[15] IBIS World Report (2012) African American hair manufacturing in the US: Market research report. http://www.ibisworld.com/industry/african-american-hair-product-manufacturing.html

[16] Desmond-Harris, J. (2009) Why Michelle’s hair matters. Time, 174, 55-57.

[17] Haley, A. (1973) The Autobiography of Malcolm X, as told to Alex Haley. A One World Book, New York.

[18] Bey, J. (2011) Going natural requires lots of help. New York Times. http://www.nytimes.com/2011/06/09/fashion/hair-care-for-african-americans.html?_r=0

[19] Bodenhorn, H. and Ruebeck, C. (2007) Colourism and African American wealth: Evidence from the nineteenth century south. Journal of Population economics, 20, 599-620. http://dx.doi.org/10.1007/s00148-006-0111-x

[20] Hall, R. (1992) Bias among African Americans regarding skin color: Implications for social work practice. Research on Social Work Practice, 2, 479-486. http://dx.doi.org/10.1177/104973159200200404

[21] Hughes, M. and Hertel, B.R. (1990) The significance of color remains: A study of life chances, mate selection, and ethnic consciousness among Black Americans. Social Forces, 68, 1105-1120. 
[22] Hunter, M. (2002) “If you're light you're alright”: Light skin color as social capital for women of color. Gender and Society, 16, 175-193.

[23] Hurston, Z.N. (1937) Their eyes were watching God. HarperCollins, New York.

[24] Levine, P. (2008) The state of undress: Nakedness and the colonial imagination. Victorian Studies, 50, 189-219. http://dx.doi.org/10.2979/VIC.2008.50.2.189

[25] White, B.S. (2003) Latter-day emancipation! Woman, dance and healing in Jamaican dancehall culture. Agenda, 58, 77-83.

[26] Solly, S., Moojen G. and Lindfors, B. (1985) Courting the Hottentot Venus. Africa: Rivistatrimestraledi stud e Documentazione dell' Istitutoitaliano per l'Africael'Oriente, 40, 133-148.

[27] Carson, L. (2009) "I am because we are”: Collectivism as a foundational characteristic of African-American college student identity and academic achievement. Social Psychology of Education, 12, 327-344. http://dx.doi.org/10.1007/s11218-009-9090-6

[28] Chavous, T., Bernat, D., Schmeelk-Cone, K., Caldwell, C., Kohn-Wood, L. and Zimmerman, M. (2003) Racial identity and academic attainment among African American adolescents. Child Development, 74, 1076-1090. http://dx.doi.org/10.1111/1467-8624.00593

[29] Robinson, J. and Biran M. (2006) Discovering self: Relationships between African identity and academic achievement. Journal of Black Studies, 37, 46-68. http://dx.doi.org/10.1177/0021934704273149

[30] Bonvillain, J.F. and Honora, D. (2004) Racial identity attitudes, self-esteem, and academic achievement among African American adolescents. Reports/Research.

[31] Byrd, C. and Chavous, T. (2009) Racial identity and academic achievement in the neighborhood context: A multilevel analysis. Youth Adolescence, 38, 544-559. http://dx.doi.org/10.1007/s10964-008-9381-9

[32] Chavous, T.M., Rivas-Drake, D., Smalls, C., Griffin, T. and Cogburn, C. (2008) Gender matters too: The influences of school discrimination and racial identity on academic engagement among African American adolescent boys and girls. Developmental Psychology, 44, 637-654. http://dx.doi.org/10.1037/0012-1649.44.3.637

[33] Cokley, K. and Chapman, C. (2008) The roles of ethnic identity, anti-white attitudes, and academic self-concept in African American student achievement. Social Psychology of Education, 11, 349-365. http://dx.doi.org/10.1007/s11218-008-9060-4

[34] Eccles, J., Wong, C. and Peck, S. (2006) Ethnicity as a social context for the development of African American adolescents. Journal of School Psychology, 44, 407-426. http://dx.doi.org/10.1016/j.jsp.2006.04.001

[35] Gordon, D., Iwamoto, D., Ward, N., Potts, R. and Boyd, E. (2009) Mentoring urban Black middle school male students: Implications for academic achievement. Journal of Negro Education, 78, 277-289.

[36] Nasim, A., Roberts, A., Harrell, J. and Young, H. (2005) Non-cognitive predictors of academic achievement for African Americans across cultural contexts. The Journal of Negro Education, 74, 344-358.

[37] Oyserman, D., Kemmelmeier, M., Fryberg, S., Brosh, H. and Hart-Johnson, T. (2003) Racial-ethnic self-schemas. Social Psychology Quarterly, 66, 333-347. http://dx.doi.org/10.2307/1519833

[38] Degruy, J. (2006) Post-traumatic slave syndrome: America’s legacy of enduring injury and healing. Uptown Press, Baltimore.

[39] Wise, L., Palmer, J., Reich, D., Cozier, Y. and Rosenberg, L. (2012) Hair relaxer use and risk of uterine leiomyomata in African-American women. American Journal of Epidemiology, 175, 432-440. http://dx.doi.org/10.1093/aje/kwr351

[40] (2000) Hair Relaxers: Chemical Market Reporter. General Science Collection.

[41] Etemesi, B. (2007) Impact of hair relaxers in women in Nakuru, Kenya International. Journal of Dermatology, 46, 2325. http://dx.doi.org/10.1111/j.1365-4632.2007.03458.x

[42] Healy, M. (2011) 'Natural’ hair making waves among Black women. USA Today. http://yourlife.usatoday.com/your-look/story/2011-12-21/Natural-hair-is-making-waves-among-black-women/52147456/1

[43] Rosenberg, M. (1965) Society and the adolescent self-image. Princeton University Press, Princeton. 


\begin{tabular}{|c|c|c|c|c|}
\hline On a whole, I am satisfied with my hair. & Strongly Agree & Agree & Disagree & Strongly Disagree \\
\hline At times I think my hair is no good at all. & Strongly Agree & Agree & Disagree & Strongly Disagree \\
\hline I feel that my hair has a number of good qualities. & Strongly Agree & Agree & Disagree & Strongly Disagree \\
\hline I am able to care for my hair as well as most other people. & Strongly Agree & Agree & Disagree & Strongly Disagree \\
\hline I feel I do not have much to be proud of about my hair. & Strongly Agree & Agree & Disagree & Strongly Disagree \\
\hline I certainly feel my hair is useless at times. & Strongly Agree & Agree & Disagree & Strongly Disagree \\
\hline I feel that hair is of value, at least on an equal plane with others. & Strongly Agree & Agree & Disagree & Strongly Disagree \\
\hline I wish I could have more respect for my hair. & Strongly Agree & Agree & Disagree & Strongly Disagree \\
\hline All in all, I am inclined to feel that my hair has failed me. & Strongly Agree & Agree & Disagree & Strongly Disagree \\
\hline I take a positive attitude toward hair. & Strongly Agree & Agree & Disagree & Strongly Disagree \\
\hline
\end{tabular}

Appendix B. Rosenberg self esteem scale (1965).

1) On the whole, I am satisfied with myself.

2) * At times, I think I am no good at all.

3) I feel that I have a number of good qualities.

4) I am able to do things as well as most other people.

5) * I feel I do not have much to be proud of.

6) * I certainly feel useless at times.

7) I feel that I'm a person of worth, at least on an equal plane with others.

8) *I wish I could have more respect for myself.

9) *All in all, I am inclined to feel that I am a failure.

10) I take a positive attitude toward myself.

$\begin{array}{cccc}\text { Strongly Agree } & \text { Agree } & \text { Disagree } & \text { Strongly Disagree } \\ \text { Strongly Agree } & \text { Agree } & \text { Disagree } & \text { Strongly Disagree } \\ \text { Strongly Agree } & \text { Agree } & \text { Disagree } & \text { Strongly Disagree } \\ \text { Strongly Agree } & \text { Agree } & \text { Disagree } & \text { Strongly Disagree } \\ \text { Strongly Agree } & \text { Agree } & \text { Disagree } & \text { Strongly Disagree } \\ \text { Strongly Agree } & \text { Agree } & \text { Disagree } & \text { Strongly Disagree } \\ \text { Strongly Agree } & \text { Agree } & \text { Disagree } & \text { Strongly Disagree } \\ \text { Strongly Agree } & \text { Agree } & \text { Disagree } & \text { Strongly Disagree } \\ \text { Strongly Agree } & \text { Agree } & \text { Disagree } & \text { Strongly Disagree } \\ \text { Strongly Agree } & \text { Agree } & \text { Disagree } & \text { Strongly Disagree }\end{array}$

